UCID- 21521

\title{
SEISMIC MONITORING OF THE JUNE, 1988 SALTON SEA SCIENTIFIC DRILLING PROGRAM FLOW/INJECTION TEST
}

\author{
S. P. Jarpe \\ P. W. Kasameyer \\ L. J. Hutchings \\ T. F. Hauk
}

This is an informal report intended primarily for internal or limited external distribution. The opinions and conclusions stated are those of the author and may or may not be those of the Laboratory.

Work performed under the auspices of the U.S. Department of Energy by the Lawrence Livermore National Laboratory under Contract W-7405-Eng-48.

\section{DISCLAIMER}

This report was prepared as an account of work sponsored by an agency of the United States Government. Neither the United States Government nor any agency thereof, nor any of their employees, makes any warranty, express or implied, or assumes any legal liability or responsibility for the accuracy, completeness, or usefulness of any information, apparatus, product, or process disclosed, or represents that its use would not infringe privately owned rights. Reference herein to any specific commercial product, process, or service by trade name, trademark, manufacturer, or otherwise does not necessarily constitute or imply its endorsement, recommendation, or favoring by the United States Government or any agency thereof. The views and opinions of authors expressed herein do not necessarily state or reflect those of the United States Government or any agency thereof. 
This document was prepared as an account of work sponsored by an agency. of the United States Government. Neither the United States Government nor the University of California nor any of their employees, makes any warranty, express or implied, or assumes any legal llability or responsibility for the accuracy, completentess, or usefulness of any information, apparafus, product, or process disclosed, or represents that its use would not infringe privately owned rights. Reference herein to any specific commercial products, process, or service by trade name, trademark, manufactures, or otherwise, does not necessarily constitute or imply its endorsement, recommendation, or favoring by the United States Government or the University of California. The views and opinions of anthors expressed herein do not necessarily state or reflect those of the United States Governinent or the University of California, and thall not be used for advertising or product endorsement purposes.

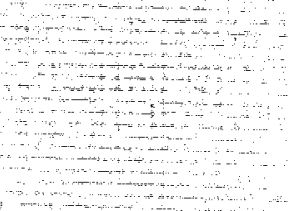

Printed in the United States of America Available from

National Technical Information Service

U.S Department of Commerce

5285 Port Royal Road

Springfield, VA 22161

Price

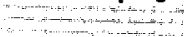

Code

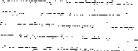

A01

\section{Papercopy Prices}

\begin{tabular}{ll}
\hline 102 & $001-050$ \\
A03 & $051-100$ \\
A04 & $101-200$ \\
A05 & $201-300$ \\
A06 & $301-400$ \\
A07 & $401-500$ \\
A08 & $501-600$ \\
A09 & 601
\end{tabular}




\section{DISCLAIMER}

This report was prepared as an account of work sponsored by an agency of the United States Government. Neither the United States Government nor any agency Thereof, nor any of their employees, makes any warranty, express or implied, or assumes any legal liability or responsibility for the accuracy, completeness, or usefulness of any information, apparatus, product, or process disclosed, or represents that its use would not infringe privately owned rights. Reference herein to any specific commercial product, process, or service by trade name, trademark, manufacturer, or otherwise does not necessarily constitute or imply its endorsement, recommendation, or favoring by the United States Government or any agency thereof. The views and opinions of authors expressed herein do not necessarily state or reflect those of the United States Government or any agency thereof. 


\section{DISCLAIMER}

Portions of this document may be illegible in electronic image products. Images are produced from the best available original document. 


\title{
Seismic Monitoring of the June, 1988 Salton Sea Scientific Drilling Program Flow/Injection Test
}

\author{
S. P. Jarpe, P. W. Kasameyer, L. J. Hutchings, and T. F. Hauk \\ Lawrence Livermore National Laboratory \\ P. O. Box 808 L-205 \\ UCID--21521 \\ Livermore, CA 94550 \\ DE89 001857
}

\begin{abstract}
The purpose of the seismic monitoring project was to characterize in detail the micro-seismic activity related to the Salton Sea Scientific Drilling Program (SSSDP) flow-injection test in the Salton Sea Geothermal Field. Our goal was to determine if any sources of seismic energy related to the test were observable at the surface. We deployed our recording stations so that we could detect and locate both impulsive microearthquakes and continuous seismic noise energy.

Our network, which was sensitive enough to be triggered by magnitude 0.0 or larger events, found no impulsive microearthquakes in the vicinity of the flow test in the 8 month period before the test and only one event during the flow test. This event has provided the opportunity to compare the detection and location capabilities of small networks and arrays in a geothermal environment.

At present, we are carefully scanning all of the data that we.collected during the flow test for evidence of anomalous seismic noise sources and for impulsive events smaller than the network detection threshold (magnitude 0.0).
\end{abstract}

\section{Background}

Geothermal reservoirs often produce detectable geophysical signals both before and during production. These signals, if understood, could provide valuable information about the processes taking place within the reservoir. This kind of information can be used to guide reservoir development strategies. Some geophysical signals, such as resistivity and gravity, are well understood, and their contribution to reservoir engineering models has been demonstrated in many geothermal fields. Other geophysical signals, including seismic 
signals, are not so well understood. Lawrence Livermore National Laboratory (LLNL) has a program to collect case histories of surveys of geophysical signals produced during injection and production of geothermal fields. In this paper, we describe a case study of seismic signals produced during a small-scale injection-production test at the Salton Sea Geothermal Field.

Several different types of seismic signals have been observed in geothermal areas. Lowfrequency $(<20 \mathrm{~Hz})$ tectonic earthquakes associated with geothermal production have been observed at the Geysers Geothermal Field [Eberhart-Phillips and Oppenheimer, 1984]. Acoustic emissions (high-frequency microearthquakes) have been observed during hydraulic fracturing at Fenton Hill [Fehler and Bame, 1985], and during reservoir production in Japan [Niitsuma et al., 1985]. Geothermal "noise" (anomalously high seismic signals having no clear onset and lasting longer than several tens of seconds) has been observed near several geothermal areas [Douze and Laster (1979), Goforth et al., (1972)].

The flow-injection test conducted as the second phase of the SSSDP provided an opportunity to study seismic signals associated with the initial fluid production from a well-studied area. During the first phase of the SSSDP, the State 2-14 well was drilled to a depth of $3 \mathrm{~km}$. During the flow/injection test, fluids produced from an open section of State 2-14 between approximately $2000 \mathrm{~m}$ and $3200 \mathrm{~m}$ depth were injected into Imperial 1-13, about $600 \mathrm{~m}$ to the north (Fig. 1). The flow continued for approximately 30 days. We installed a seismic recording system to monitor microearthquakes and continuous seismic noise signals associated with the initial production of these two wells.

\section{Seismic Network Description and Data Collection Procedure}

Figure 1 shows the configuration of the LLNL seismic stations during the flow test. Two sets of stations were deployed; 1) seven three-component stations within a $3 \mathrm{~km}$ radius of the two wells, which we will refer to as the network stations, and 2) three small groups of six to nine sensors within a $100 \mathrm{~m}$ square area, which we will refer to as arrays A, B, and C. The network of three-component stations, which provide primarily phase arrival times, was used to detect and locate microearthquakes in the traditional manner. The network of three arrays, which can provide direction, velocity, and depth information for any incoming seismic energy, was used to monitor all possible low-frequency $(3-25 \mathrm{~Hz})$ sources of seismic energy originating from the flow/injection zone.

The seismic signals were digitized at each station at a rate of 120 samples/sec and the digital signals transmitted to the central recording site located near well 2-14. The frequency range covered by the three-component stations was 1 to $30 \mathrm{~Hz}$. The arrays were optimized for signals between 3 and $25 \mathrm{~Hz}$. All of the sensors were buried several inches below the ground surface.

Our recording procedure during the flow/injection test was designed to detect both the impulsive and continuous sources of energy. To record microearthquakes, an event detection process at the central recording site monitored all of the signals continuously and archived all 


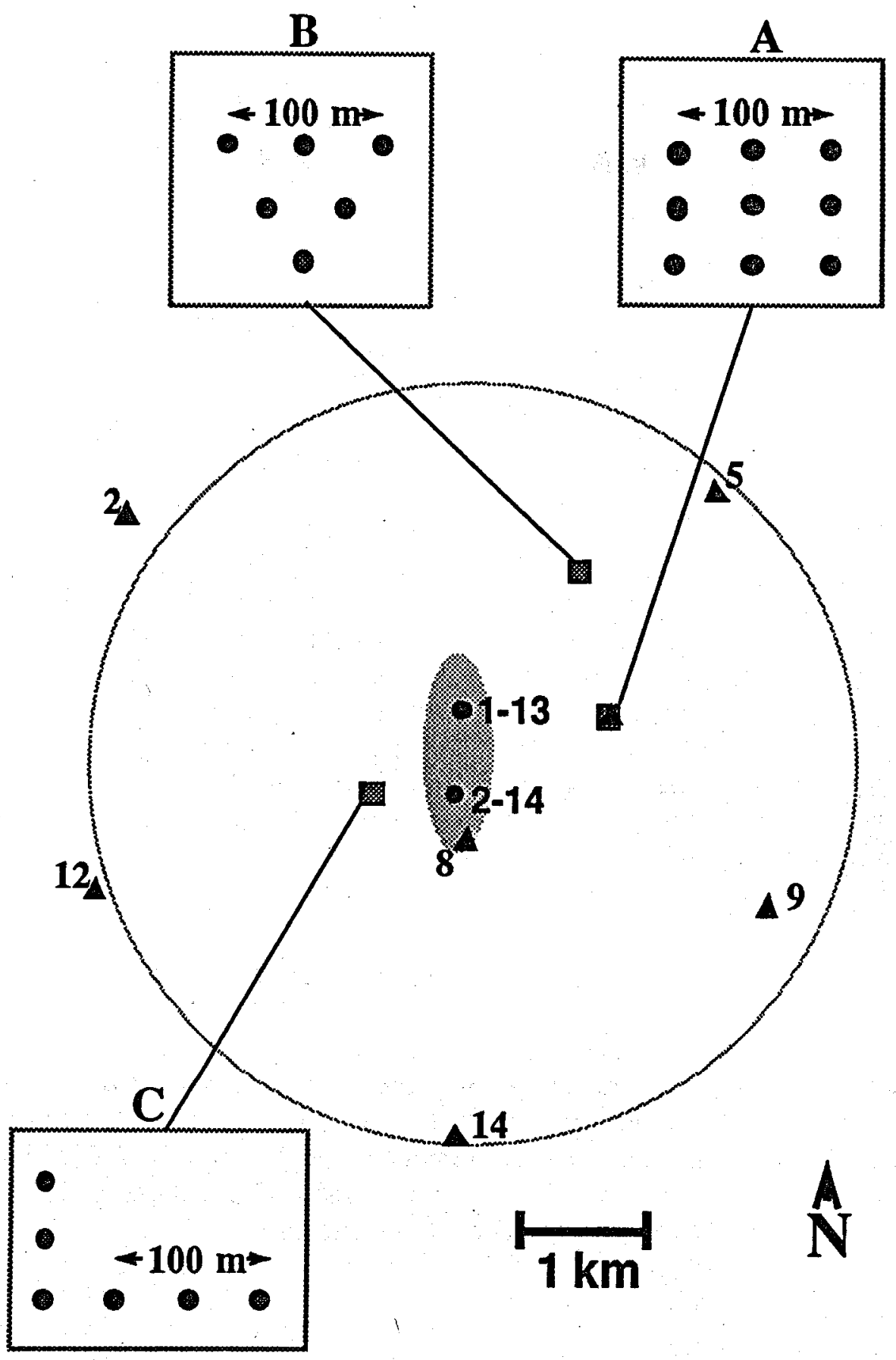

Figure 1. Map of the LLNL seismic network during the June, 1988 flow/injection test. The triangles are three-component station locations and the squares are the array locations. The insets show the geometries of the arrays A, B, and C. The shaded elliptical zone delineates the area within which we expected to see seismic activity related to the test. 
of the waveforms when a detection threshold set to produce an acceptable false alarm rate was exceeded at the required number of stations. To record continuous sources and/or impulsive events smaller than the network detection threshold, we archived data for two minutes twice an hour. This recording network and recording system is capable of detecting all types of events previously seen in geothermal fields, except for acoustic emissions with dominant frequencies greater than $30 \mathrm{~Hz}$.

\section{Microearthquake Monitoring}

We monitored the flow test zone for background seismicity between Sept. 1987 and the beginning of the flow test on June 2, 1988. During this time, the system operated in the event-detect mode. We have not finished processing the data, but between Sept. 1987 and March 1988, no detectable microearthquakes occurred within the zone. We have recorded numerous earthquakes located just outside our network, however, and from the size of these events can estimate the lower detection threshold of our system to be magnitude 0.0 .

Preliminary results from the data collected during the flow/injection test do not indicate any microearthquake activity larger than magnitude 0.0 within the zone of interest. This negative result indicates that neither stress nor thermal effects were large enough to induce microearthquakes larger than this threshold during the shallow test. We are continuing to process the data to search for both smaller magnitude microearthquakes and continuous energy sources that may have occurred before and during the flow test. By searching the two-minute force-recorded segments, we have so far been able to detect one event that will be discussed in detail below.

\section{Analysis of Flow Event}

When State 2-14 was first opened, we recorded a single small (magnitude -0.5) seismic event followed a few seconds later by an air wave. We have not yet determined the cause of this signal, but it provides us an opportunity to compare the monitoring capabilities provided by the traditional networks with the experimental array methods. We will present here in detail the information that we have been able to infer about these signals using both the seven station three-component network and the three arrays.

\section{Characteristics of Flow Event}

Three vertical component waveforms for the flow event are plotted in Figure 2. The event-tostation distance is increasing from the top to the bottom trace. The seismic wave and the air wave are clearly differentiated by the difference in moveout across the network.

The same information can be obtained by computing the narrow band 2-dimensional wavenumber [Aki and Richards, 1980] from the signals at one of the arrays (array A). Figure 3 shows contour plots of power as a function of the narrow band 2-dimensional 


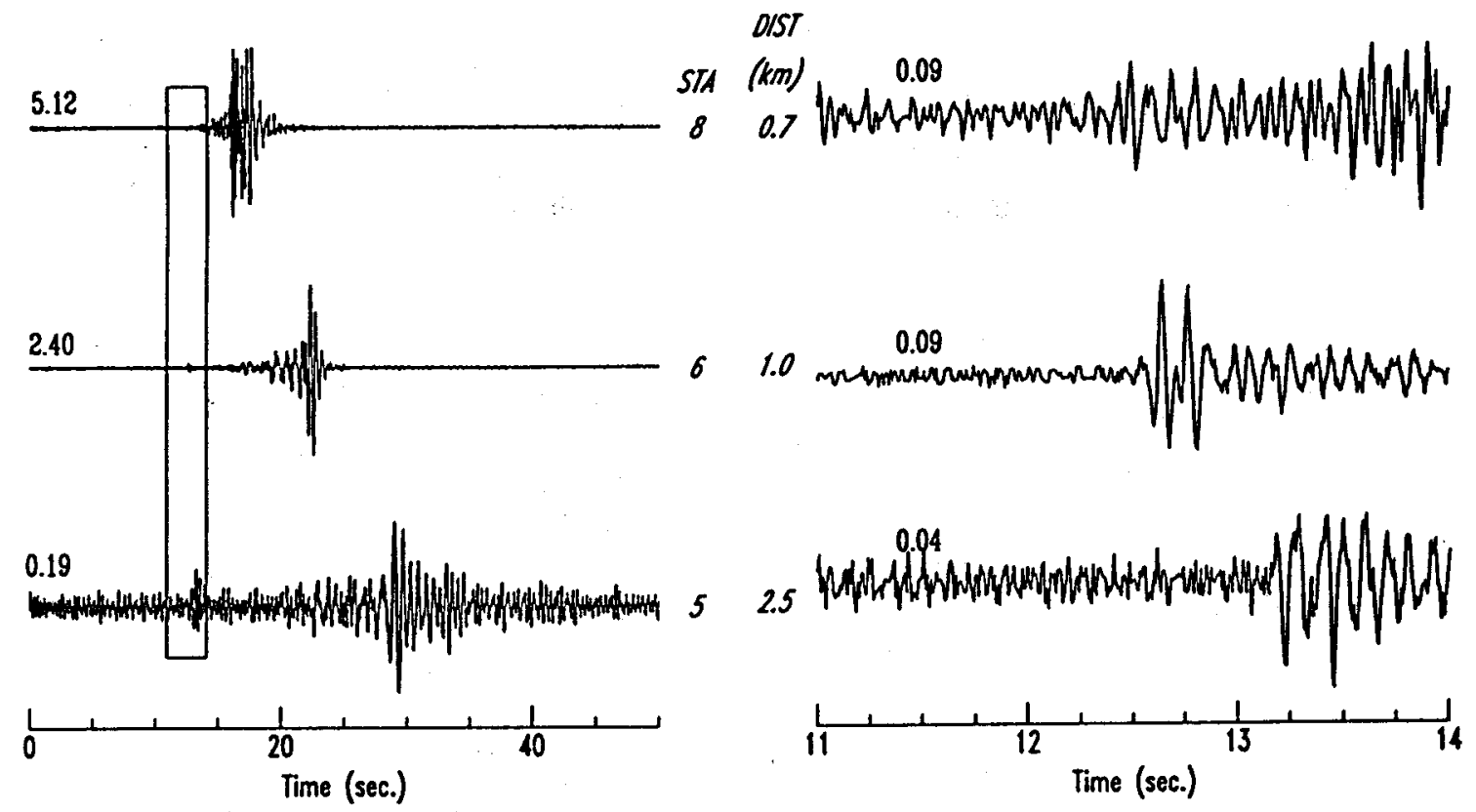

Figure 2. Seismograms from the flow event from stations at three different distances. At left is a 50 second segment dominated by the high-amplitude air wave. At right is the smaller seismic portion of the signal enclosed by the box in the left figure. Zero time is June 2, 1988 00:41:44, 10 minutes after State 2-14 was opened. The number above each trace is the maximum amplitude of the seismogram times $10^{-4} \mathrm{~nm} / \mathrm{sec}$. The distance between the station and the event is shown between each pair of traces.

NORTH

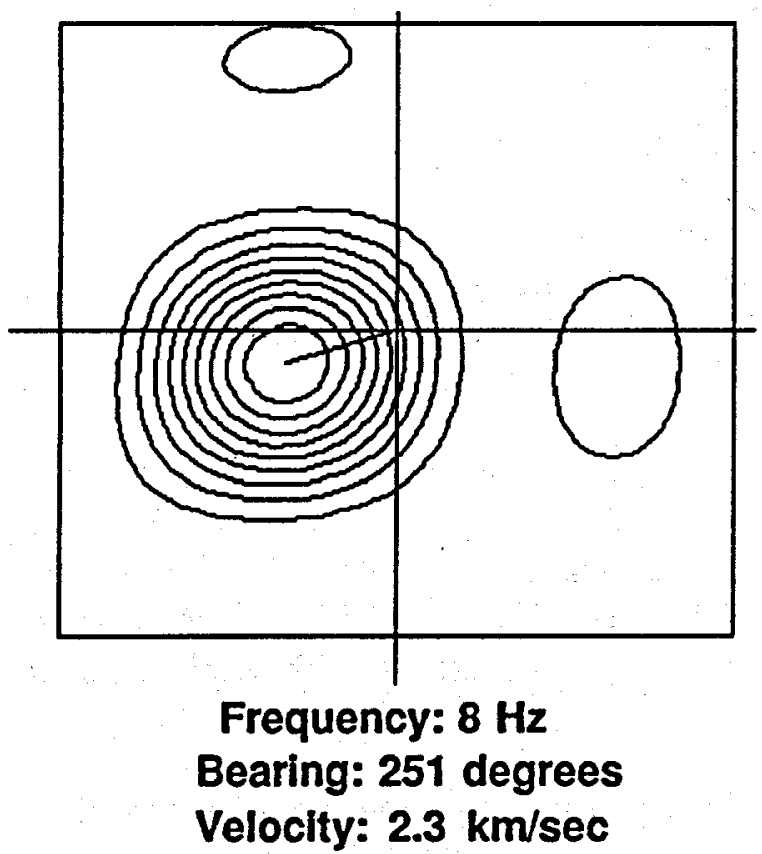

NORTH

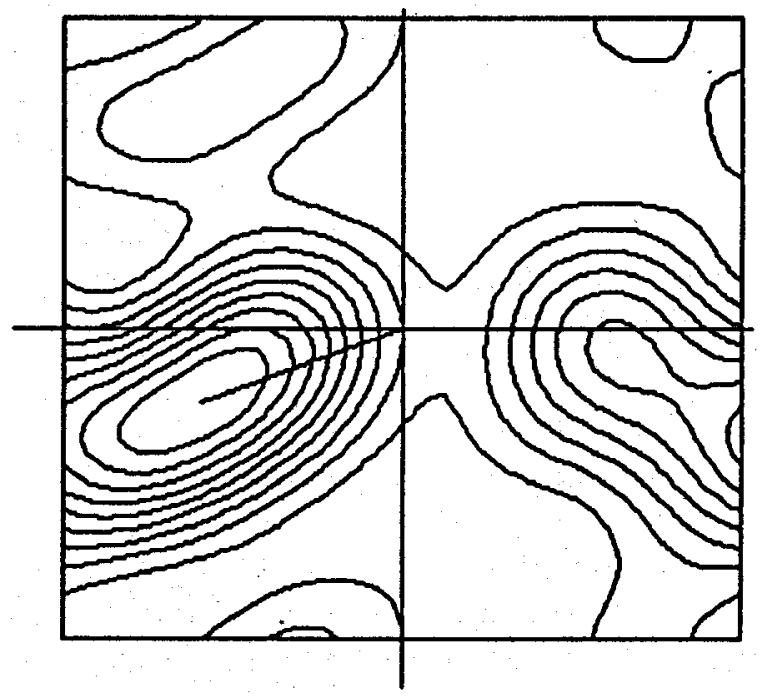

Frequency: $3 \mathrm{~Hz}$ Bearing: 248 degrees Velocity: $0.47 \mathrm{~km} / \mathrm{sec}$

Figure 3. Contours of narrow-band 2-dimensional wavenumber power for the seismic (left) and air (right) waves recorded at array $\mathbf{A}$. The bearing is measured clockwise from north. The wavenumber is $0 \mathrm{~km}^{-1}$ at the center and $10 \mathrm{~km}^{-1}$ at the edge of the plot. 
wavenumber for the air wave and the seismic phase. The azimuth of arrival is obtained from the azimuthal position of the peak power. The wavenumber of the arrival is obtained from the radial position of the peak. The apparent velocity is the ratio of the frequency at which the spectrum is calculated and the observed peak wavenumber.

It can be seen from Figure 3 that the two phases are arriving from the same azimuth, but that their apparent velocities are quite different. For the air wave, the frequency is $3 \mathrm{~Hz}$ and the peak wavenumber is $6.4 \mathrm{~km}^{-1}$, yielding a velocity of $0.47 \mathrm{~km} / \mathrm{sec}$., which is slightly higher than the velocity of sound $(0.33 \mathrm{~km} / \mathrm{sec}$.). For the seismic wave, the frequency is $8 \mathrm{~Hz}$ and the peak wavenumber is $3.48 \mathrm{~km}^{-1}$, resulting in an apparent velocity of $2.3 \mathrm{~km} / \mathrm{sec}$.

\section{Location of Flow Event}

We were able to determine the location of the seismic phase using both the 3-component network and the arrays. The network location was obtained from the P-and S-arrival times at 5 of the stations by using a standard location algorithm. The array location was obtained by estimating the bearing from each of the three arrays.

We used a standard location algorithm [HYPO71 (Revised), Lee and Lahr, 1973] to locate the seismic phase using the phase arrival times. The algorithm finds the hypocentral location that minimizes the sum of the squares of the travel-time residuals. The velocity model was derived from vertical seismic profile (VSP) data from well 2-14 interpreted by Daley et al., 1988

The epicentral location for the event derived from the network arrival times is shown on Figure 4, and the depth calculated for the event is $900 \mathrm{~m}$. We estimate that the uncertainty in this location is $200 \mathrm{~m}$ vertically and $300 \mathrm{~m}$ horizontally. The area defined by the epicentral location and its uncertainties is shown on Figure 4 as a circle with a radius of $300 \mathrm{~m}$.

The location defined by the three arrays is obtained graphically from the intersection of the bearing measurements from the three arrays, as shown in Figure 4 . The uncertainty in each of the beams ( \pm 3 degrees) is illustrated by the shaded wedges emanating from the arrays.

\section{Depth Estimation for Flow Event}

The depth of the source can also be estimated using the arrays. To obtain absolute depth, precise information about the velocity model is needed. This can be obtained from independent sources such as VSP data, or by calibration of the arrays with explosions or earthquakes at several different known depths.

Because the event we are studying is fairly shallow, we can use a simple velocity model to estimate the depth from the array data. The material under the array is saturated alluvium, which has a seismic velocity of $1.5 \mathrm{~km} / \mathrm{sec}$. According to a nearby seismic refraction study by Frith (1978), the velocity increases to $2.0 \mathrm{~km} / \mathrm{sec}$ at a depth of about $100 \mathrm{~m}$. We can use this velocity model to calculate the depth of our source from the apparent velocity observed by the 


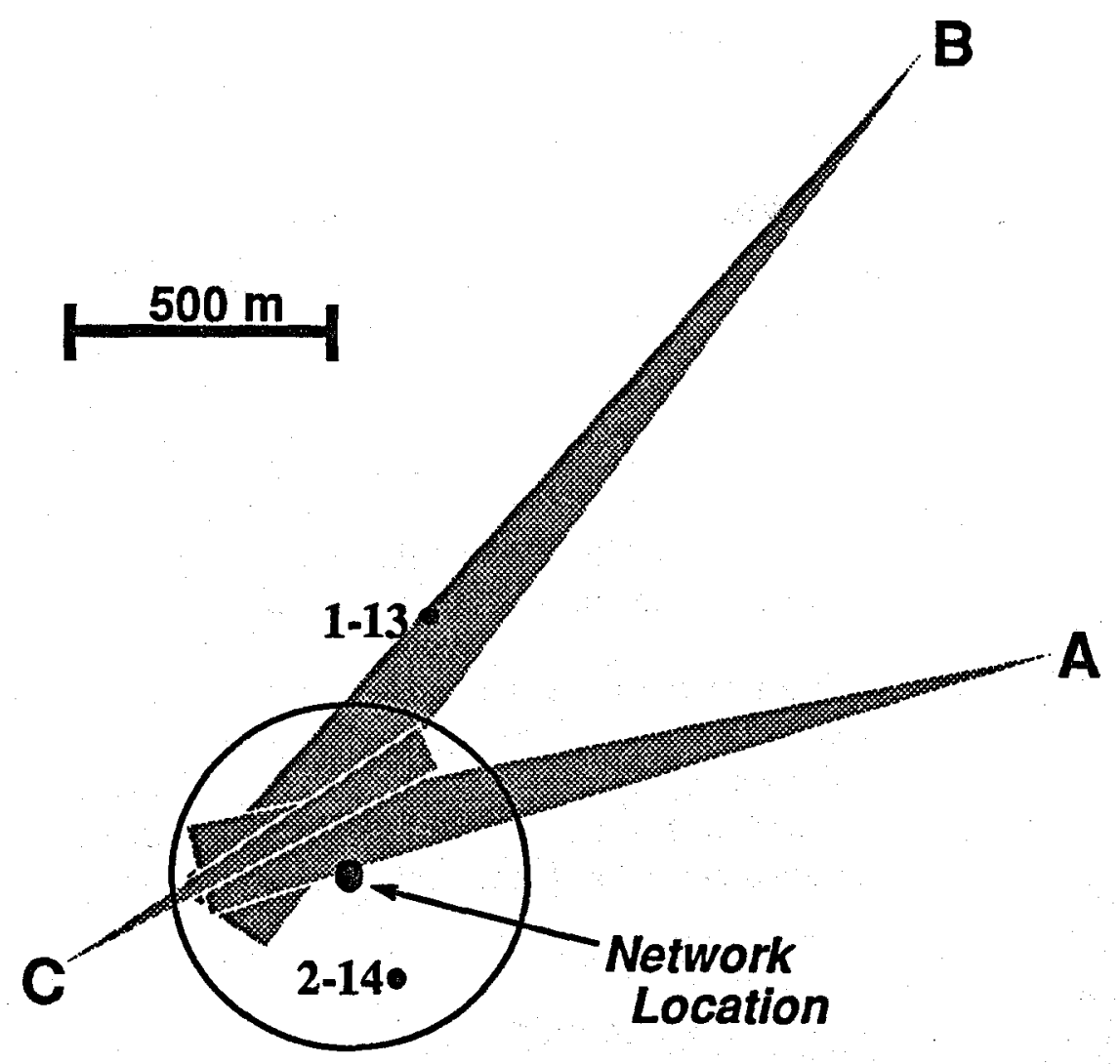

Figure 4. Summary of location results for the seismic part of the flow event. The array location is defined by the intersection of the beams from the three arrays. The network location is obtained from the arrival times at the network stations. The uncertainty in the network location $(400 \mathrm{~m})$ is indicated by the circle centered on the location. The network and array locations are the same, within the uncertainties of each measurement.

array. Using the observed apparent velocity of $2.3 \mathrm{~km} / \mathrm{sec}$, and a horizontal distance of 1500 $\mathrm{m}$, the calculated depth is $900 \mathrm{~m}$.

For deeper events, depth calculation becomes more difficult because more layers are involved and refracted arrivals have to be considered. For this reason, calibration with earthquakes or explosions is desired. If calibrations are not available, the arrays can still be used to determine relative depths of events.

\section{Discussion/Conclusions}

The lack of microseismicity associated with this flow test is probably a result of the fact that the pressures produced by the injection were not high enough to induce stresses sufficient to fracture the relatively weak, highly permeable material in which the flow took place. The origin of the event we analyzed here is still not known. We do know that it occurred within $400 \mathrm{~m}$ of well 2-14 shortly after the well was opened. The event seems to have occurred at a 
depth $(1100$ to $700 \mathrm{~m})$ shallower than the open section of the well $(3200$ to $2000 \mathrm{~m})$. The timing of the arrival of the air wave suggests that it originated at the depth of the seismic phase and propagated up to the surface via the open well.

The data that we have analyzed allows us to assess the capability of the relatively unproven array methods compared to the more traditional network methods. The network provides better locations if events are large (greater than magnitude 0.0 for this network) and impulsive. The arrays, on the other hand, are more useful when the events are smaller and not recorded well by all of the network stations. This is primarily a result of their ability to enhance the signal amplitude relative to the noise. Our example event, which was not recorded well by all of the network stations, bears this out because the uncertainty in the array location appears to be smaller than the uncertainty in the network location (Figure 4).

Another advantage of the arrays that we have not been able to illustrate here is their ability to provide information about seismic sources that are not impulsive. This includes continuous noise sources and events with onsets that are not clearly identifiable. These kinds of signals cannot be located with arrival time location methods, but the arrays can be used in the same way that we used them to locate the event analyzed in this paper.

\section{Acknowledgments}

We would like to acknowledge the contributions of Craig Johnston, Don Rock, and Dan Ewert to the fielding of the seismic network. Unocal Geothermal Division and KennecottAustralia Exploration Ltd. provided instrument sites. Bechtel Corporation provided support at the recording site. This work was performed under the auspices of the U.S. Department of Energy by the Lawrence Livermore National Laboratory under Contract W-7405-Eng-48. Funding was provided by the Department of Energy Geothermal Technology Division.

\section{References}

Aki, K., and P. G. Richards (1980). Quantitative Seismology: Theory and Methods, (Volume 2) ch. 11, sec. 4.

Daley, T. M., T. V. McEvilly, and E. L. Majer, (1988). Analysis of VSP data at the Salton Sea Scientific Drilling Program, EOS, trans. Amer. Geophys. Union, 68, 16, p. 445 (Abstract).

Douze, E. J., and S. J. Laster, (1979). Seismic array noise studies at Roosevelt Hot Springs, Utah geothermal area, Geophysics 44, 1570-1583.

Eberhart-Phillips, D., and D. H. Oppenheimer, (1984). Induced Seismicity in the Geysers Geothermal Area, California, Journal of Geophysical Research 89, 1191-1207 
Frith, B. R., (1978). A Seismic refraction investigation of the Salton Sea Geothermal Area, Imperial Valley, California, (Master's thesis, U. C. Riverside).

Goforth, T. T., E. J. Douze, and G. G. Sorrells, (1972). Seismic noise measurements in a geothermal area, Geophysical Prospecting 20, 76-82.

Lee, W.H.K, and J.C. Lahr, (1975). HYPO71 (Revised): A computer program for determining hypocenter, magnitude, and first motion pattern of local earthquakes, U.S. Geological Survey Open-file Report 75-311, 113 p.

Niitsuma, H., K. Nakatsuka, N. Chubachi, H. Yokoyama, and M. Takanohashi (1985). Acoustic emission measurement of geothermal reservoir cracks in Takinoue (Kakkonda) field, Japan, Geothermics 14, 525-538. 


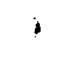

$\gamma$

.

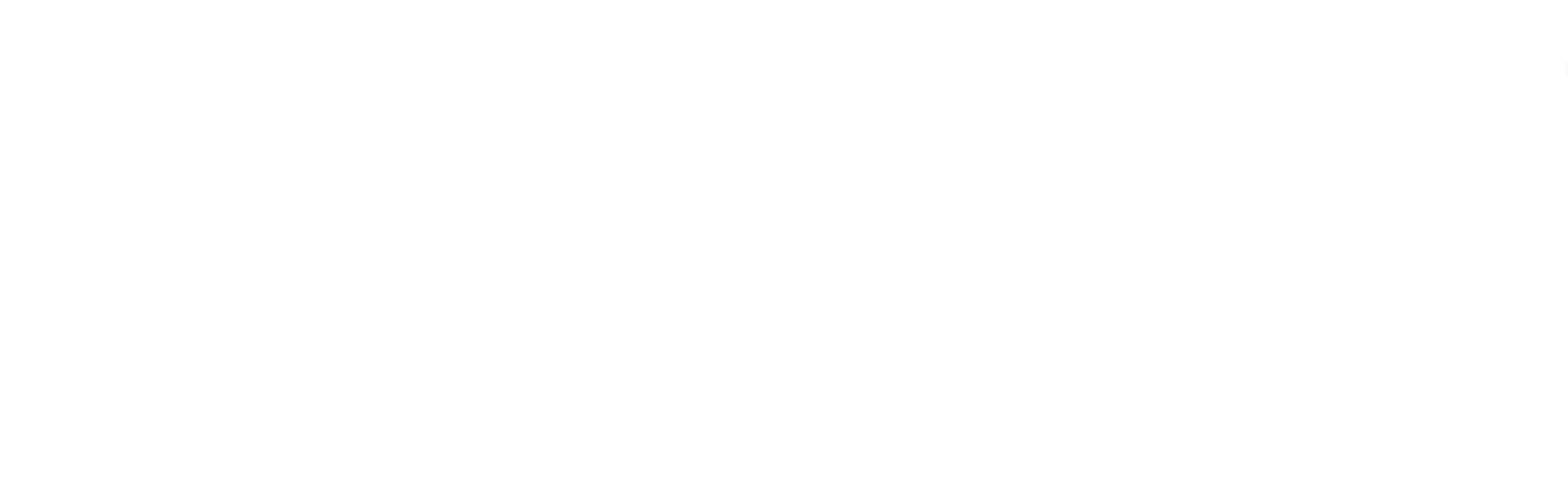



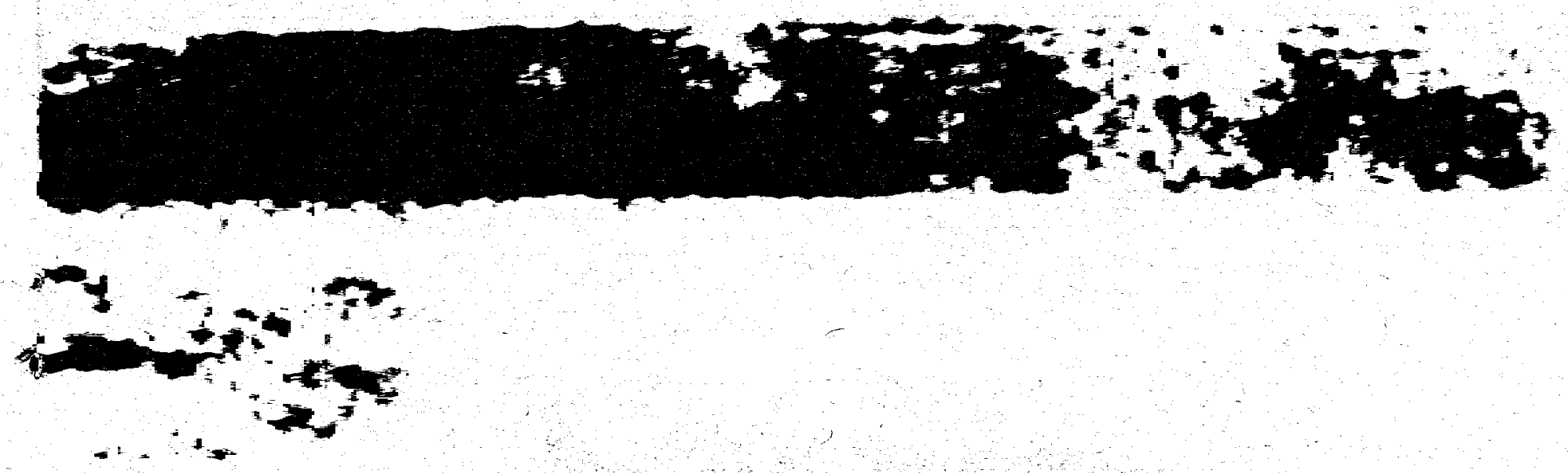


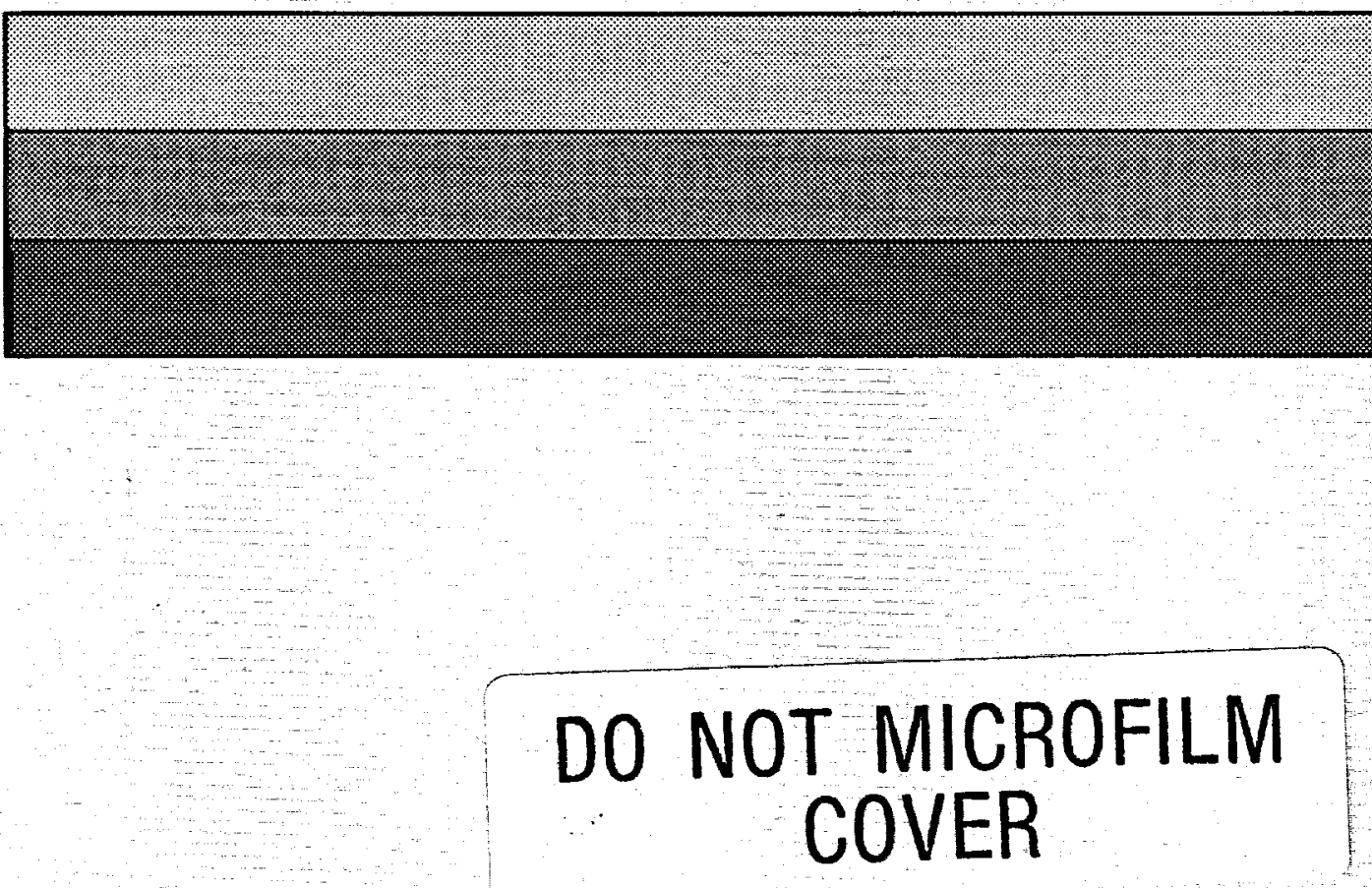

